\title{
8. CONTROLLED-SOURCE SEISMIC EXPERIMENT AT HOLE 581C 1
}

\author{
Fred K. Duennebier, Barry Lienert, Robert Cessaro, Paul Anderson, and Subhashis Mallick, \\ Hawaii Institute of Geophysics ${ }^{2}$
}

\begin{abstract}
Seismic refraction lines fired to ocean bottom seismometers (OBS) and to the ocean sub-bottom seismometer (OSS) at Site 581 provide some of the highest quality refraction data yet obtained in the deep ocean. A particularly useful subset of these data had a Soviet air gun as a source and an OBS as a receiver. Excellent data with a shot spacing of less than $250 \mathrm{~m}$ are well recorded out to a range of $45 \mathrm{~km}$. These data are analyzed with WKBJ, $\tau-p$ inversion, and reflectivity modeling which are used to obtain seismic models. The resulting model for the Northwest Pacific crust agrees with that obtained by Anosov et al. (1982) for the same region. It differs from "standard" ocean crust models in that it contains a low-velocity zone for both $\mathbf{P}$ and $\mathrm{S}$ waves near the top of Layer 3. Strong shear conversion at the base of the sediments is easily identified on the different components, yielding an accurate sediment shear velocity of $210 \mathrm{~m} / \mathrm{s}$. The value of using a very large air gun as a refraction source and geophones as sensors is obvious from the results obtained.
\end{abstract}

\section{INTRODUCTION}

A large controlled-source experiment had been planned in conjunction with the emplacement of the Defense Advanced Research Projects Agency (DARPA) (Ballard, this volume) and Hawaii Institute of Geophysics (HIG) (Byrne et al., this volume) borehole seismic systems on Leg 88 . The U.S.N.S De Steiguer was to shoot several explosive and sparker lines over the instruments for structural and propagation studies. An array of ten ocean bottom seismometers (OBSs) was deployed by the U.S.N.S De Steiguer on 1 August 1982 to record the shooting. All instruments were on timed releases and were retrieved on 12 August. All but one of the instruments recorded data on continuous analog tape; the other recorded digitally and operated for only a short time.

Despite two attempts, a hole acceptable for emplacement of the DARPA Marine Seismic System (MSS) could not be drilled. As the time was approaching for the OBSs to return to the surface, shooting of about 250 shots to the OBS array was begun on 9 September. The Soviet research vessel Dimitri Mendeleev also deployed OBSs in the area and fired a large (30-liter) air gun across the site from the north. When the HIG ocean sub-bottom seismometer (OSS IV) (Byrne et al., this volume) was installed on 11 September 1982, the OBSs were already returning to the surface. An additional 180 shots were fired by the U.S.N.S De Steiguer. Some of these were recorded by OBSs from Oregon State University (Bibee and Bee, in press), but most were recorded only by the borehole instrument.

Although all data are of good quality, the most valuable data were recorded by an HIG isolated-sensor ocean bottom seismometer (Byrne et al., 1983) from the 30-liter Soviet air gun. The air gun was towed at a depth of $12 \mathrm{~m}$

\footnotetext{
${ }^{1}$ Duennebier, F.K., Stephen, R., Gettrust, J.F., et al., Init. Repts. DSDP, 88: Washington (U.S. Govt. Printing Office).

2 Address: Hawaii Institute of Geophysics, University of Hawaii, 2525 Correa Road, Honolulu, HI 96822.
}

and operated at a pressure of about $100 \mathrm{~Pa}$ (Y. Neprochnov, pers. comm., 1984). The excellent recording fidelity, high shot density, strength, and repeatability of the source combine to yield an extremely useful data set. More than 200 shots are analyzed over a range of 50 $\mathrm{km}$. Although the line is single-ended (recorded from only one direction), lateral structure is minimal (Bibee and Bee, in press), and conclusions drawn are easily extended to the other directions by comparison with the refraction lines fired by the U.S.N.S. De Steiguer.

The experiment site (Hole 581C) is located in old crust ( $\sim 110 \mathrm{Ma})$ about $40 \mathrm{~km}$ south of the Hokkaido Trough and about $400 \mathrm{~km}$ west of Hokkaido, in the northwest Pacific basin (Fig. 1). Single-channel reflection data (Fig. 2) show pelagic sediments roughly $350 \mathrm{~m}$ thick, smoothly draped over ocean crust. Drilling of holes at Site 581 on Legs 86 and 88 encountered continuous pelagic siliceous clays with occasional chert bands becoming numerous near the base of the sediments. The basement consists of massive basalt. Typical water depth in the area is $5500 \mathrm{~m}$. A detailed site survey is found in Grim and Gettrust (this volume). Several investigations of the ocean crust in this region have been published, including one from Leg 88 itself (Bibee and Bee, in press). Asada and Shimamura (1976) published data from a single OBS in the area, and Anosov et al. (1982) published air-gun refraction results from an OBS in an area to the south.

\section{DATA REDUCTION AND PROCESSING}

Only the air-gun data recorded by one OBS will be discussed in detail. Other record sections from the OSS and other OBS data (lines shown in Fig. 3) will be presented in the discussion section for comparison with the models obtained from the air-gun data. Reduction and analysis of the data obtained from the Soviet air gun was delayed until the source data were received from Dr. Neprochnov (Chief Scientist on the Dimitri Mendeleev) more than 1 yr. after the experiment took place. The section of analog tape containing these data was then 


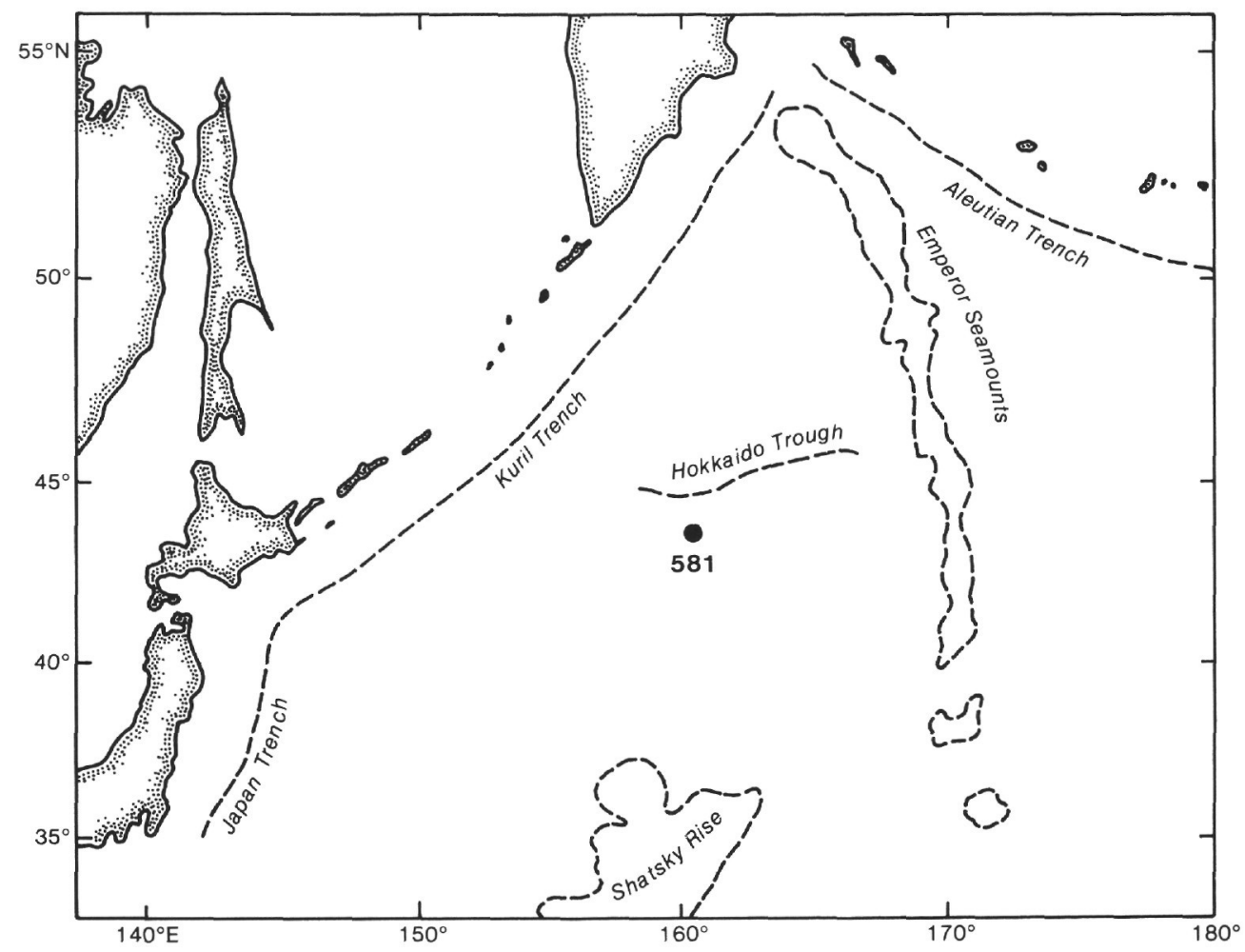

Figure 1. Map showing locations of the ocean sub-bottom seismometer (OSS IV) experiment at DSDP Site 581.

digitized at 80 samples/s, demultiplexed, and gain corrected. Data were plotted reduced to water-wave velocity, and minor navigational problems were corrected based on direct water-wave traveltimes. No corrections were applied for water-depth variations $(<100 \mathrm{~m})$ or shot signature. More complete analyses are planned, including deconvolution.

\section{DISCUSSION}

The unfiltered record sections for the three components of data are shown in Figure 4, reduced to a velocity of $8 \mathrm{~km} / \mathrm{s}$ (i.e., a phase arrival with a velocity of 8 $\mathrm{km} / \mathrm{s}$ would arrive at the same time at all ranges). The high quality of these data is obvious, becoming even more obvious when compared with recordings of shots fired by the U.S.N.S. De Steiguer recorded on the same OBS (Fig 5). The shot data suffer in comparison because of variations in shot size and shot depth (which change the source signature) and a much larger distance between shots. Also, many of the De Steiguer shots were large enough to severely overload the OBS analog tapes, thus reducing fidelity of recording. As the Soviet air gun was fired once per minute, and the HIG OBSs are allowed to change gain automatically once per minute, these data were optimal for our recording system.

A cursory look at Figure 4 shows that the hydrophone and vertical and horizontal sensors each recorded different portions of the energy arriving at the OBS. It is important, therefore, to review the capabilities of each sensor. Hydrophones record omnidirectional changes in pressure and are insensitive to shear; therefore, all of the arrivals in Figure 4a are compressional in nature-none are shear. Any arrivals with shear velocities must have been converted to compressional before returning to the water. The vertical geophone records the vertical component of particle velocity for waves arriving at the OBS. Arrivals on geophones can be either compressional or shear. Note that Figure $4 \mathrm{~b}$, the vertical component, shows far more arrivals than Figure 4a. All of the arrivals not seen on the hydrophone (e.g., D, E, and F) must be shear arrivals with some portion of their energy causing vertical motion of the geophone. (As will be discussed later, it appears that the shear arrivals on the vertical have very little vertical motion, but are caused by crosscoupling with horizontal motion in the sensor package.) Arrivals seen on both Figures $4 \mathrm{a}$ and $4 \mathrm{~b}$ are compressional arrivals (e.g., A, B, and C). The horizontal geophone is sensitive to motion along its axis in the horizontal plane. Again, the motion can be either compressional or shear. Arrivals in Figures $4 a$ and $4 c$ that are contemporaneous must be compressional in nature with a component of their motion in the horizontal direction (e.g., C and G). Arrivals in Figure $4 c$ that are not seen in Figure 4a must be shear (e.g., D, E, and F). Note that several of the arrivals on the hydrophone (Fig. 4a) and vertical (Fig. 4b) are not observed or are weak on the horizontal (Fig. 4c), such as arrivals A and B. The above arguments require that arrivals A and B are nearly vertically traveling compressions when they arrive at the OBS. Similarly, arrivals D and E are strong on the horizontal but absent on the hydrophone, and relatively small on the vertical; therefore, they must be shear arrivals traveling in the near-vertical direction at the OBS. Those familiar with refraction record sections will immediately 


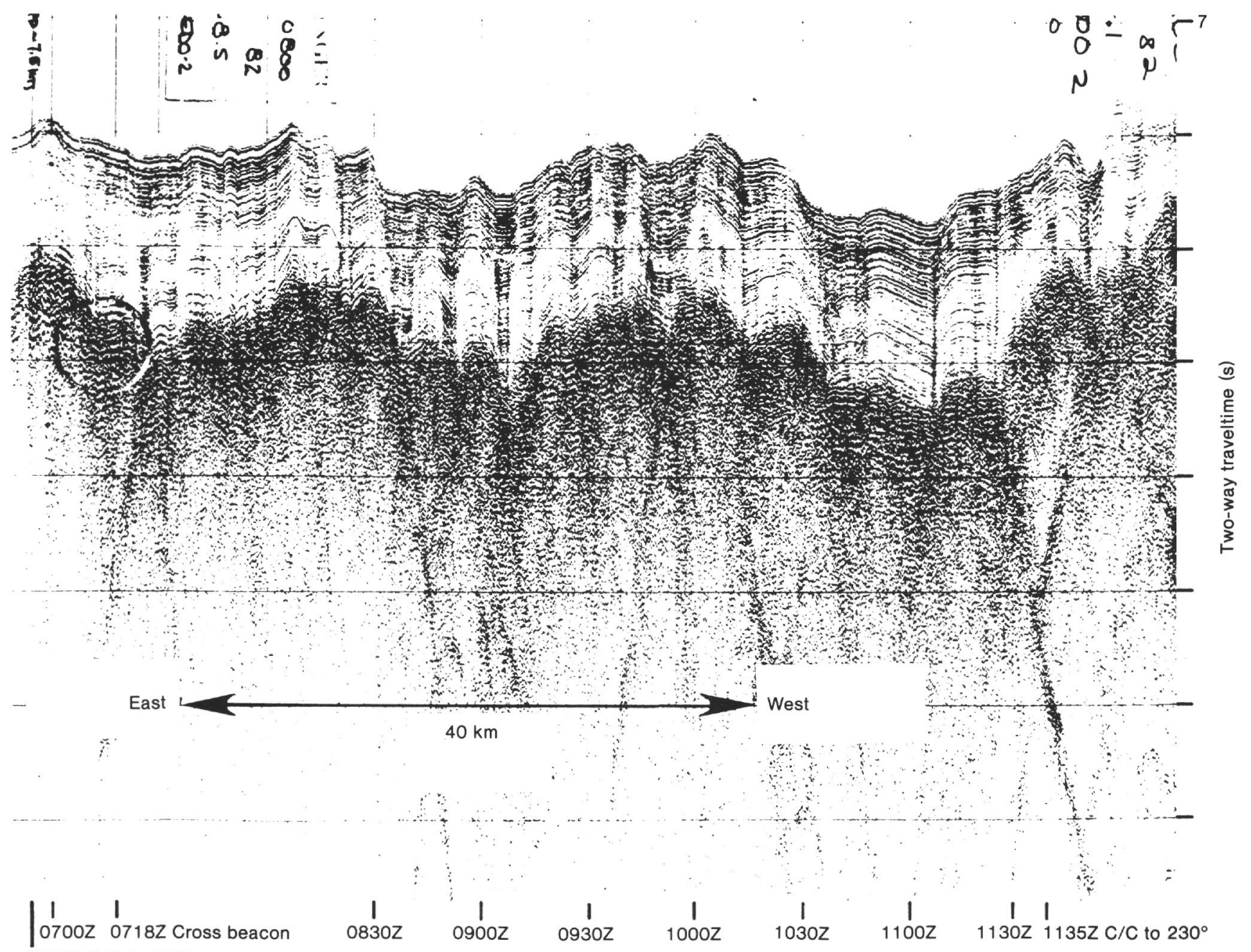
$0655 \mathrm{Z} / \mathrm{C}$ to $280^{\circ}$

Figure 2. East-west water-gun reflection profile over Site 581 (Glomar Challenger, Leg 86). Location of OSS IV is shown by the circle on the left.

The OBS recordings discussed were made at a site directly over the OSS.

recognize that arrivals $\mathrm{A}$ and $\mathrm{D}$ have compressional velocities and B and E have shear velocities. Arrival D must have converted to shear prior to detection, and arrival B must have converted from shear to compressional. Signals arriving before the first water wave (arrival C) are traveling nearly vertically because of the strong velocity decrease from the crust to the sediments.

Cursory observations of these records also show that if the hydrophone and vertical component sections are each delayed along the time axis by about $1.8 \mathrm{~s}$ relative to the horizontal section, then arrivals $\mathrm{A}, \mathrm{B}$, and $\mathrm{C}$ on the hydrophone and vertical become coincident in time with arrivals D, E, and F on the horizontal. This delay time is the added time necessary to travel one way through the sediments at the shear velocity rather than the compressional velocity.

Three analysis techniques were used on these data to obtain seismic models: the WKBJ technique (Chapman, 1978), $\tau-p$ inversion (using the methods of Kennett and Orcutt [1976], Jackson [1972], and Wiggins [1972]), and forward modeling with the reflectivity method (Fuchs and Müller, 1971). Additional constraints on the models were obtained from water column velocities, sediment thickness, and single-channel reflection compressionalwave traveltimes in the sediments obtained from data collected during Legs 86 and 88 . Because the frequencies of the refracted seismic signals used are so low (below $15 \mathrm{~Hz}$ ) in data obtained from the ocean floor, the sedimentary compressional-wave velocities could not be obtained from these data. The shear velocities are so low in the sediments, however, they are easily obtained from the horizontal geophone data and the sediment thickness known from drilling.

A brief discussion of the inversion $(\tau-p)$ and forward modeling (WKBJ and reflectivity) of these data is given below, followed by comparison of the results from each method, and comparison with the data from other sources and receivers.

\section{WKBJ MODELING}

The WKBJ method utilizes seismic-ray theory to construct synthetic seismograms for a given model. The computer program used in this study was Chapman's timedomain WKBJ code described by Dey-Sarkar and Chapman (1978). The execution time is extremely fast compared to other methods, but is also often misleading, as only 


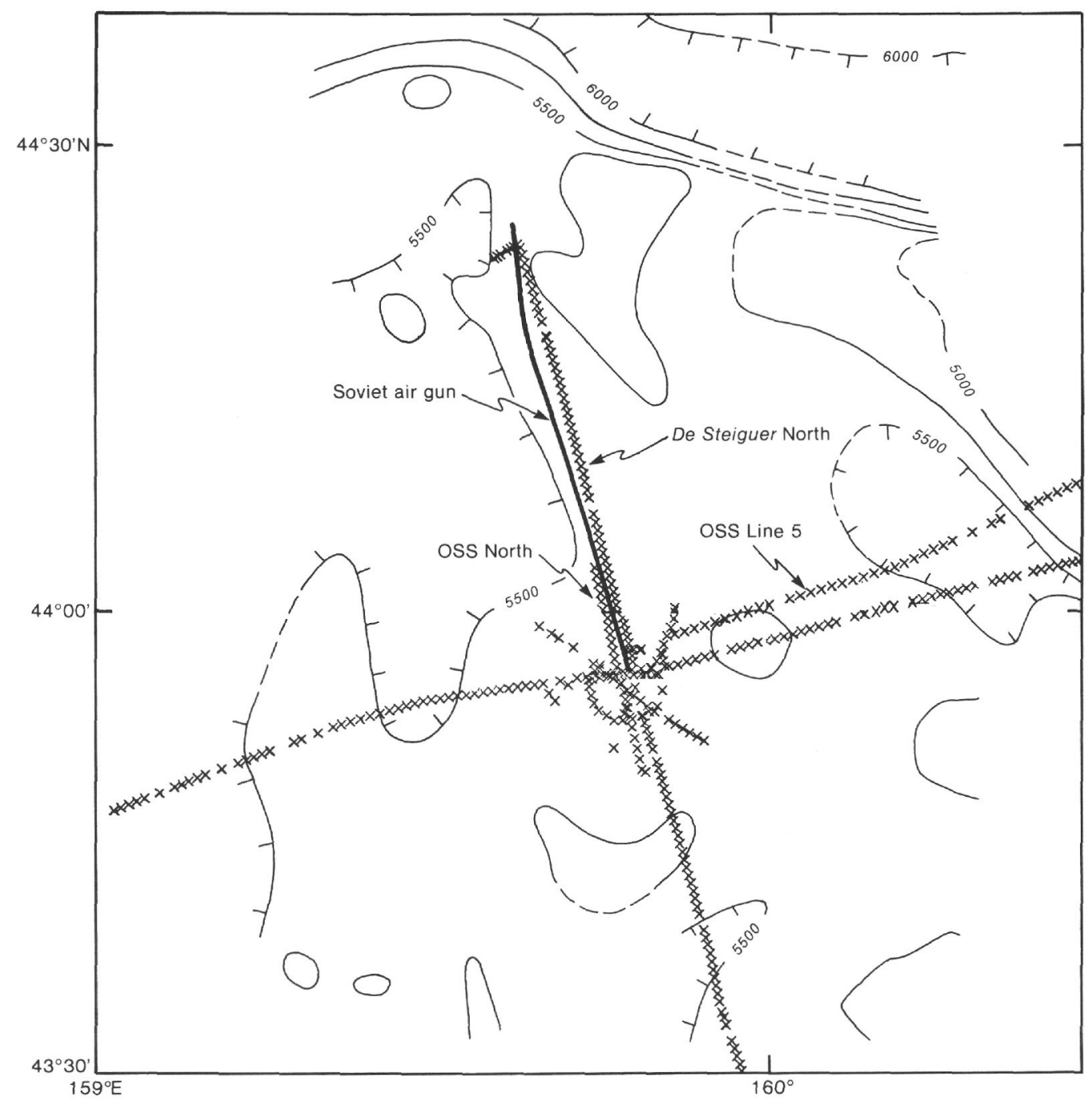

Figure 3. Map of Site 581 area showing shot lines fired during the OSS IV experiment. Data from solid lines are discussed in the text. Xs show locations of other shots. Bathymetric contours (modified from Grim and Gettrust, this volume) are at $250-\mathrm{m}$ intervals. The site location is at $43.9^{\circ} \mathrm{N}, 159.8^{\circ} \mathrm{E}$.

those seismic rays requested are calculated. On the other hand, as different rays are calculated separately and raytrace sections are part of the output, the results yield considerable insight into the modeling process. Layers with gradients and low velocity zones are allowed. An estimate of the seismic structure is obtained in a iterative process by starting with an estimate of model, then calculating synthetic record sections, and then comparing synthetic with real data to determine changes for the next iteration.

The synthetic seismograms obtained with the WKBJ method and the model shown in Figure 6 are displayed in Figure 7. Although the traveltimes for each phase are correct to $\pm 0.1 \mathrm{~s}$, the amplitudes of the arrivals differ appreciably from the data (Fig. 4), indicating either inaccuracies in the model, or failures of the WKBJ approximation (ray theories are known to suffer problems in regions of extreme gradients, and amplitudes are not accurate when obtained from models containing low-velocity zones, for example). As the WKBJ method is inexpensive, it was used in this study to obtain a "reason- able" model of the structure for input as a starting model to the much more expensive reflectivity modeling. The model obtained was not the "best possible" by any means.

\section{REFLECTIVITY METHOD}

The reflectivity method calculates solutions to the wave equation to obtain the entire seismic wave field for a particular model. Resulting synthetic seismograms are a complete representation of the seismic wave field that would be transmitted through the model. The program used was written by Mallick and Frazer (in press) using a slightly modified version of the imbedding algorithm given by Kennett (1974) and extended further by Kennett and Kerry (1979). The input to this program is a stratified (flat) earth model, bounded above by a free surface and below by a half space. Intrinsic attenuation in the model is incorporated by making the velocities complex and frequency dependent. Complete synthetic responses (comprising all multiply reflected arrivals, including free surface reflections), computed first in the frequency-ray parameter space, are transformed into the frequency-range 


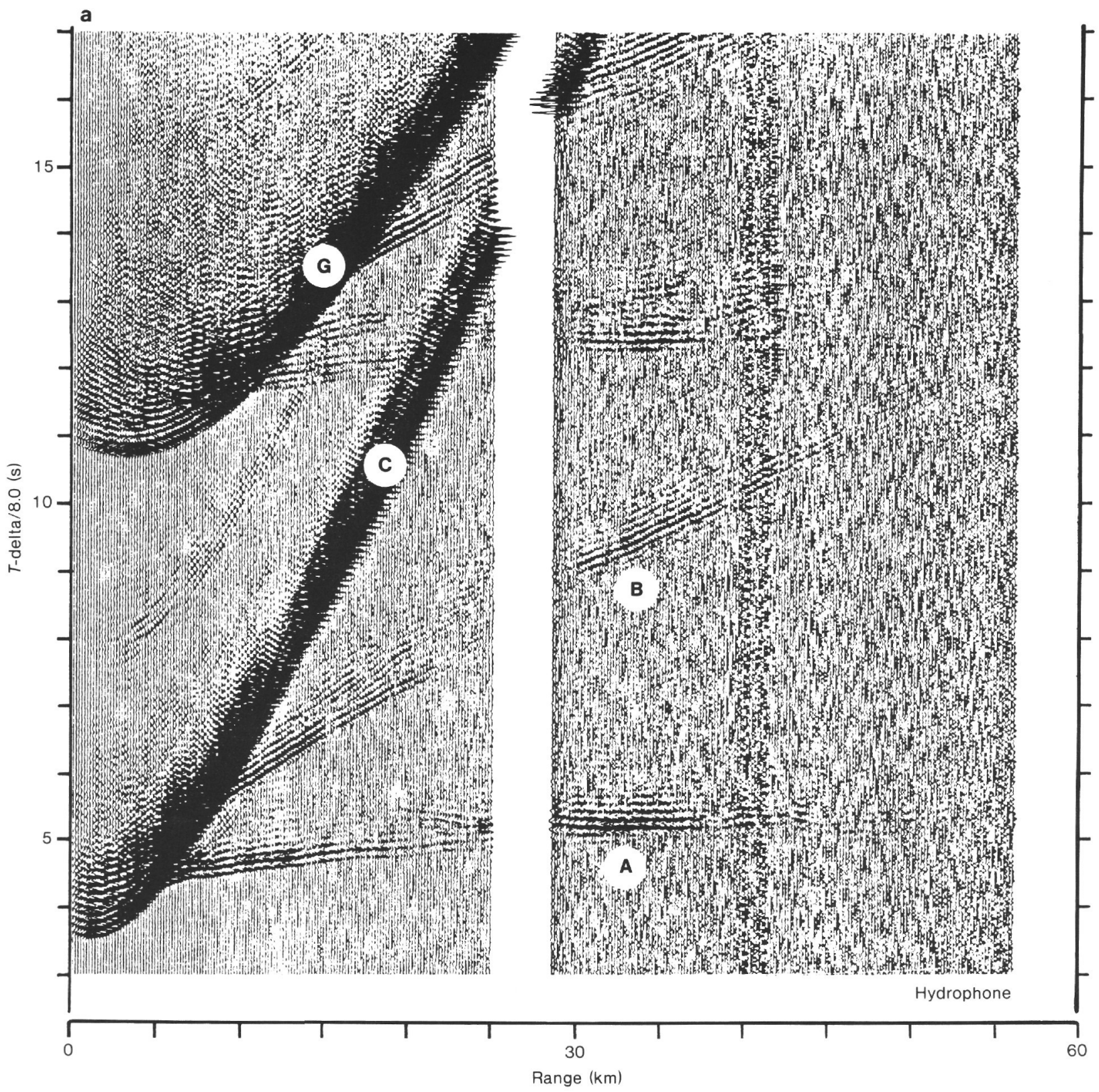

Figure 4. Ocean bottom seismometer (HIG OBS \#C220) data from Soviet air gun north of Site 581. OBS was located within $1 \mathrm{~km}$ of the site. Figure $4 \mathrm{a}$ is the pressure record section, $4 \mathrm{~b}$ is the vertical geophone, and $4 \mathrm{c}$ is the horizontal geophone. All record sections are reduced to $8 \mathrm{~km} / \mathrm{s}$, are unfiltered, and are amplitude-corrected for $r^{-1}$ spreading. The letters on arrivals refer to wave-types drawn in Figure $12 \mathrm{a}$.

domain using generalized Filon's Method (Frazer and Gettrust, 1984). The synthetic data are in turn transformed into time-range space through a standard FFT. To avoid spurious noise arising from the band-limited integral transforms stated above, the response values are tapered gently at their edges. To avoid time wrap-around, frequencies were made complex. The ray parameter was also made complex in such a way that the wave number is always real (in order to insure integration along the real wave number contours, where no singularities exist in the reflectivity function). Although a single run of the program requires up to $13 \mathrm{hr}$. of Harris $800 \mathrm{CPU}$ time, the resulting model (after approximately 15 iterations) justifies the expense. The synthetic record sections are shown in Figure 8 for the model in Figure 6. Comparison of Figures 4 and 8 shows excellent agreement of both arrival times, amplitudes, and phase relationships of nearly all arrivals on each component.

\section{$\tau-p$ INVERSION}

The data presented in Figure 4 are so dense and highly coherent from trace to trace that use of direct traveltime inversion with the $\tau-p$ method should result in a good estimate of the velocity-depth function. The $\tau-p$ method (Chapman, 1978; Stoffa et al., 1981) involves transforming the data from record section format (range vs. time) to slowness-delay time space. This is done by scalar addition of the points on each seismogram that 




Figure 4 (continued).

fall on a line with a particular time intercept $(\tau)$ and a particular slope $(p=d t / d x)$. Each of these sums is a data point in $\tau-p$ space. The data shown in Figure 4 have been transformed into the $\tau-p$ plane, and are shown in Figure 9. Head waves in a constant-velocity layer should appear as points in $\tau-p$ space, and reflections as elliptical curves. A line connecting the minimum $\tau$ arrivals will be single-valued in $p$ (unlike traveltime curves in the $x$ - $t$ plane) and will always increase with decreasing $p$. Low velocity zones, should they exist, will be represented by a step offset in $\tau$. Once the $\tau-p$ curve is obtained it can be inverted directly for the velocity-depth function by using methods such as those described by Bessanova et al. (1974), Kennett and Orcutt (1976), and Diebold and Stoffa (1981). The $\tau-p$ minimum curves for both compressional and shear waves were first obtained by examining the slant stacks in Figure 9 along with similar plots of the semblance (Stoffa et al., 1981). The $\tau-p$ curves were then used as input data to a linearized inversion following the method of Jackson (1972) and Wiggins (1972), similar to that used by Kennett and Orcutt (1976). The velocity model used was a piecewise continuous 20 layer model with constant velocity gradients in each layer. A starting model was obtained with the $\tau$-sum method described by Diebold and Stoffa (1981). The layer thicknesses were held fixed at the logarithmic spacing shown in Figure 10. Error estimates are obtained by calculating the variances of velocity estimates and resolution matrices similar to the method used by Kennett and Orcutt (1976) and using the techniques of Jackson (1972) and Wiggins (1972). In this method, the velocity-depth function, the $\tau(p)$ minimum curve, and an estimate of possible error in $\tau$ are used as input. The number of degrees of freedom is variable, allowing trade-offs between 


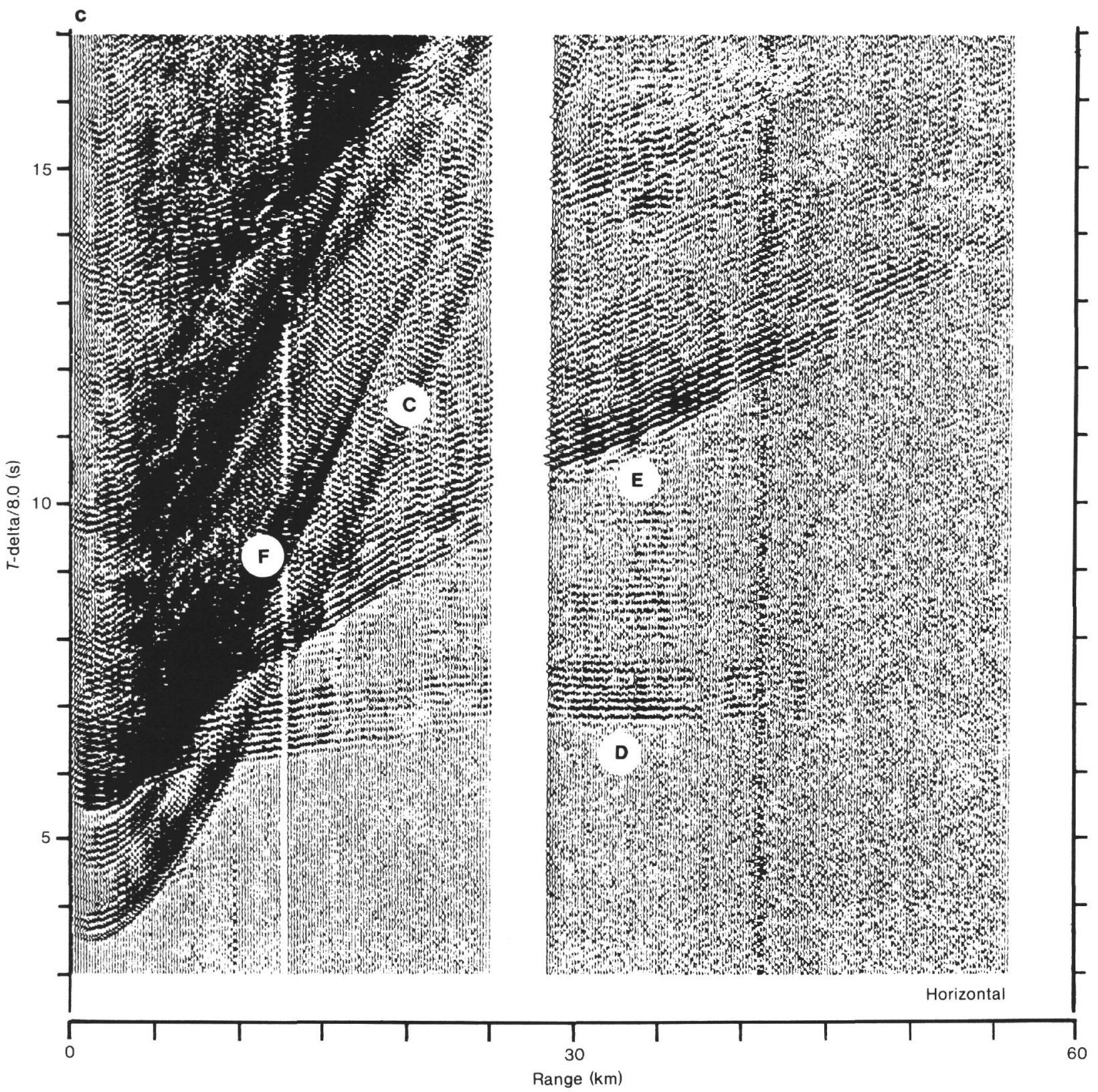

Figure 4 (continued).

velocity precision and depth resolution. The precision of velocity estimates is obtained directly from the variance of the estimates, and the resolution in depth is estimated as the depth points where the amplitudes of the resolution kernels are at half their maximum values. The results of the error analysis for the 20-layer model are shown in Figure 10, using 11 degrees of freedom for the shear model, 9 for the compressional-wave model, and assum. ing a possible error of $0.05 \mathrm{~s}$ in picking the values of $\tau$ for the $\tau(p)$ minimum curve. The velocity-depth inversion is the same curve as shown in Figure 6. The errors plotted as horizontal lines are estimates of precision of the velocity obtained from the variance, and the errors plotted as vertical lines are estimates of the depth resolution for that particular velocity obtained from the resolution matrix. We interpret these errors as yielding a range of depths in which a particular velocity is likely to occur. Note that the "precision" of the velocity estimates increases where resolution in depth decreases, especially in zones of nearly constant or decreasing velocity with depth. The model is underdetermined in these regions, and does not have enough information to sufficiently resolve velocities at each of the layer boundaries specified in the model (Kennett and Orcutt, 1976).

Slant stacks similar to those in Figure 9, but using combinations of the three recorded components that enhance different arrivals, are shown in Figure 11. When $1.8 \mathrm{~s}$ are subtracted from the horizontal traveltimes, and the data from the vertical and horizontal geophones are added (Fig. 11a), the compressional refractions are in phase and the shear refractions are out of phase, thus the compressional arrivals are enhanced relative to noise 




Figure 5. Ocean bottom seismometer (HIG OSS \#C220) data from De Steiguer refraction line north of Site 581 close to the air-gun data shown in Figure 4. (Also see Fig. 3.) Figure 5a is the pressure record section, $5 \mathrm{~b}$ is the vertical geophone, and Figure 5c is the horizontal geophone. All record sections are reduced to $8 \mathrm{~km} / \mathrm{s}$, are unfiltered, and are corrected for $r^{-1}$ spreading.

and shear arrivals. If the horizontal is subtracted from the vertical (Fig. 11b), then the compressional refraction is suppressed, and the shear arrivals are distinctly enhanced. The summation of the hydrophone and the vertical geophone data (Fig. 11c) enhances the refracted arrivals relative to noise and the direct water arrivals.

\section{COMPARISON OF MODELS}

The least accurate of the above models was that obtained by forward modeling with the WKBJ method. This is not so much a reflection on the method, but of the time and effort spent in modeling. Note that the WKBJ synthetics (Fig. 7) poorly represent the mantle reflection (PmP and SmS in Fig. 12) in that the synthetics contain energy at distances well beyond where energy is observed in the data. This discrepancy could be partially eliminated by replacing the sharp (first order) discontinuity at $7.5-\mathrm{km}$ depth with a gradient, as was done for the reflectivity modeling. The traveltime errors for the WKBJ synthetics and the data are no worse than those from the reflectivity synthetics; thus the WKBJ model would be reasonable if only traveltimes (and not amplitudes) were available. The modeling of amplitudes and later arrivals is done with the reflectivity method (Fig. 8 ). The reflectivity synthetics are in excellent agreement with the data in Figure 4.

We believe that any further improvements in the fit would require changes in the density and attenuation of the layers rather than their velocities, with the possible exception of the sediment column, where addition of 


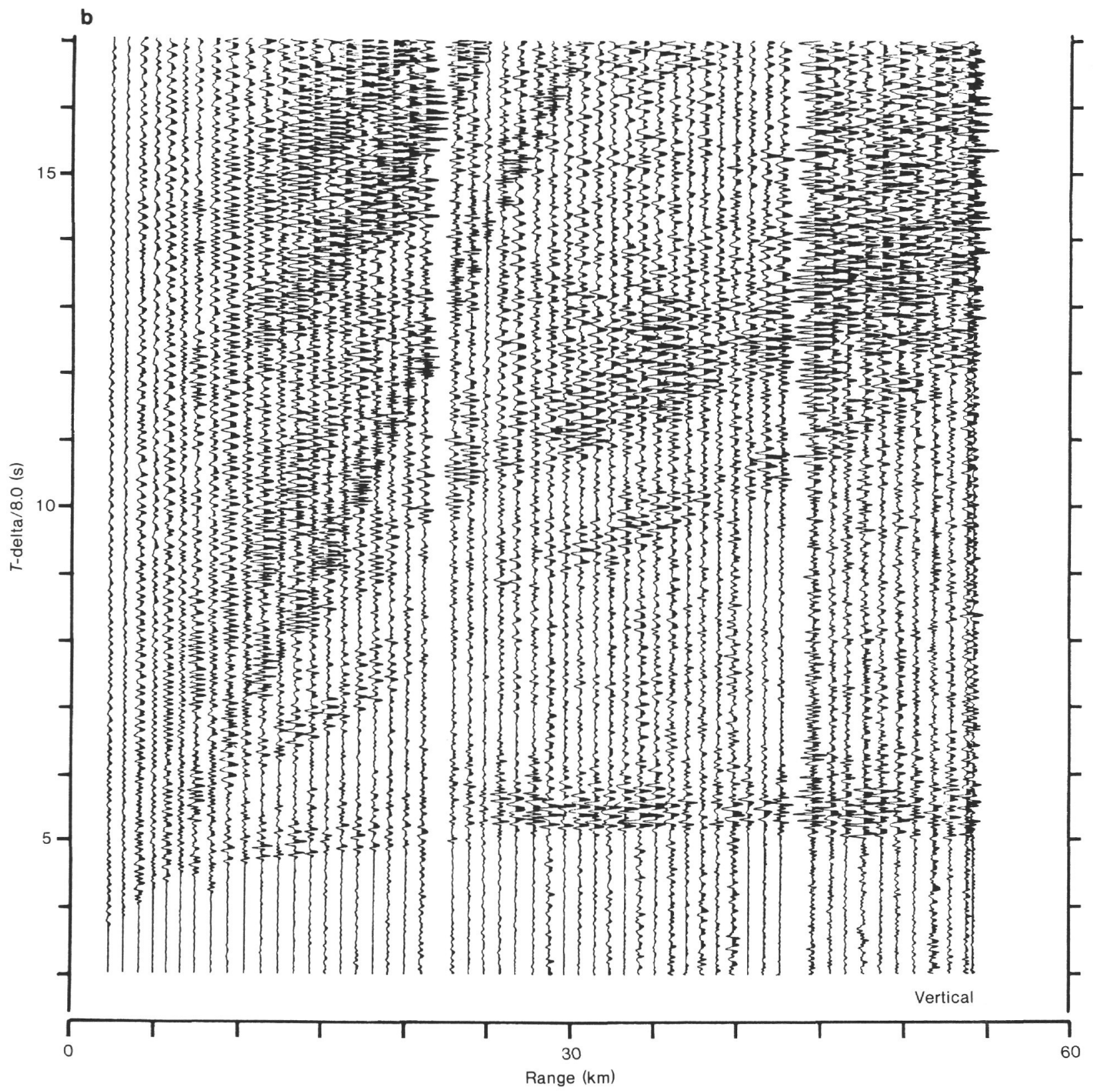

Figure 5 (continued).

the chert layers may supply the reverberation noted in the data. Although this model does an excellent job of emulating the data, we make no claims concerning its uniqueness. For example, the low-velocity zones in the upper part of Layer 3 are not well constrained, and it may be possible to eliminate at least the P-wave low-velocity zone by extending the depth of Layer 3 with a zone of constant velocity. It is unlikely that this could be done for the shear waves, however. The Moho transition zone is reasonably well constrained in velocity and shape, but its depth could increase if the low-velocity zone above it is not present. The reflectivity model obtained is very similar to the model of Anosov et al. (1982), for a region about $15^{\circ}$ to the south.

The $\tau-p$ inversion is useful in that it allows estimation of uncertainty in the model velocities and depth resolu- tion (based on linearized inversions). Comparison of the $\tau-p$ results and the reflectivity model in Figures 6 and 10 shows that the reflectivity model is within the $\tau-p$ model error bounds in all regions except in parts of Layer 2, where the $\tau-p$ minimum curve is difficult to pick.

The crustal low-velocity zone in the $\tau-p$ model is shallower and less extensive than in the reflectivity model, and the WKBJ model contains no low-velocity zone. The errors in the $\tau-p$ model within the possible low-velocity zones are a result of poor resolution caused by a lack of arrivals from within the low-velocity zone. Using only traveltimes, it is possible to find an adequate model without a low-velocity zone.

Several aspects of the structure obtained from the reflectivity modeling deserve mention. The crustal low-velocity zone, as mentioned above, appears to be neces- 


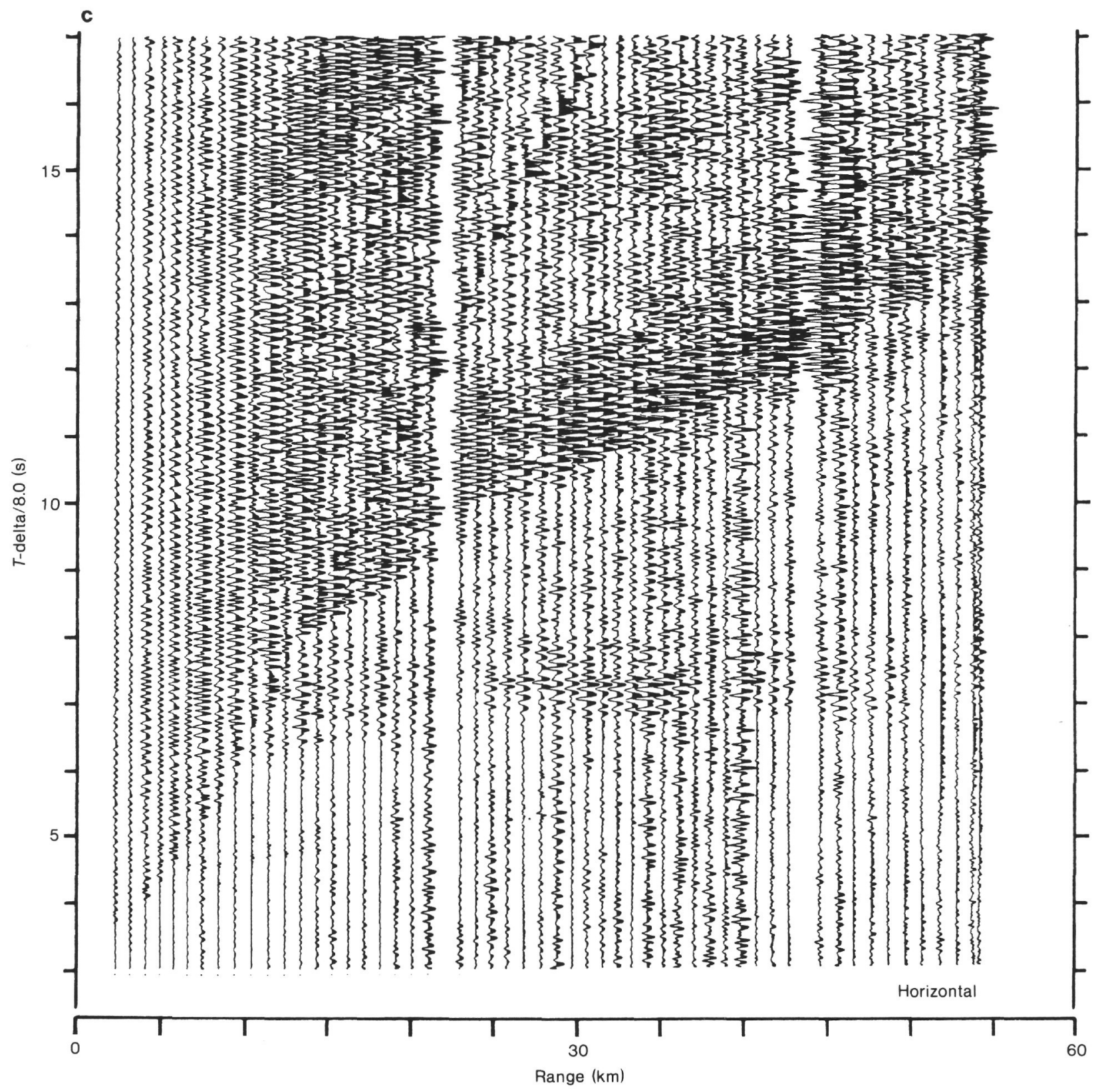

Figure 5 (continued).

sary to model adequately both the compressional and shear velocities. The crust-mantle transition is highly constrained by the amplitude in the mantle reflected phases. What appears as a smooth gradient in the model, however could easily be a layered sequence of mantle material interbedded with crustal material in the transition zone (Spudich and Orcutt, 1980a).

Note that whereas the high velocity of the compressional waves results in poor resolution (wavelength at 10 $\mathrm{Hz}>150 \mathrm{~m}$ ) in the sediment, the velocity of shear waves is low enough to allow considerable resolution (wavelength at $10 \mathrm{~Hz}$ about $20 \mathrm{~m}$ ) in the sediments. Although no attempt has been made to model shear structure in the sediment column, it should be possible even at these low frequencies.
Several arrivals observed in the data have amplitudes that are not matched by the reflection synthetic seismograms. A basement reflection arriving at a time equivalent to the round trip shear traveltime through the sediments is observed on both the pressure data and synthetics (between arrivals $\mathrm{C}$ and G on Fig. 4 at about $t=$ $7.5 \mathrm{~s})$. A shear basement refraction is related to this arrival on the pressure and vertical synthetics, but it is not observed in the data. The vertical synthetics show the poorest match to the data, mainly because of a lack of shear arrivals in the synthetics. The vertical synthetics are similar to the pressure synthetics, except for the appropriate phase changes. We believe that this difference is a result of cross coupling of horizontally polarized motion into vertical motion in the OBS geophone sen- 


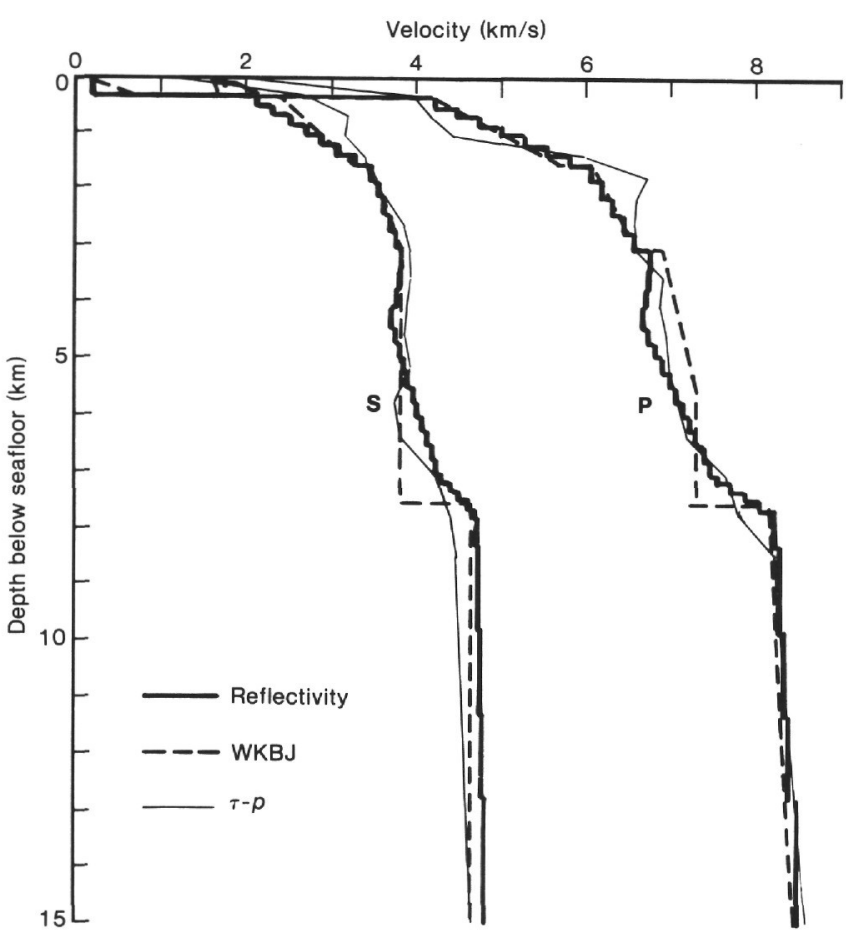

Figure 6. Velocity-depth models derived from Soviet air gun-OBS data. Of the three models shown, the reflectivity model is believed to be the most accurate. Synthetic seismograms for the WKBJ and reflectivity models are shown in Figures 7 and 8, respectively. The $\tau-p$ model error analysis is shown in Figure 10.

sor package. Horizontal ground motion apparently excites a rocking mode in the cylindrical geophone package, causing the signal to register on the vertical as well as the horizontal geophone. This type of problem is common in OBSs, and leads to the conclusion that density gradients and all asymmetries should be avoided in OBS sensor package design, and they should have as little cross section in the water as possible. Note that the direct water arrival at ranges greater than $10 \mathrm{~km}$ is considerably larger in the vertical data than the synthetic seismograms. As this arrival is becoming near horizontal, this difference again suggests cross coupling. Coupling of vertical ground motion into the horizontal geophone does not seem to be a problem. This is not surprising, as vertical motion should not cause a rocking mode of the geophone package. The horizontal synthetics yield an excellent fit to the data, although the horizontal data suggest that the shear reflection from the base of the sediments (arrival pgs in Fig. 12) should have larger amplitude at ranges greater than $5 \mathrm{~km}$ than shown in the synthetics. Also, the reverberation in the shear arrivals is not modeled well by the synthetics. The reverberation could be the result of imperfect coupling or layering (cherts?) in the sediment column.

\section{COMPARISON WITH OTHER DATA}

The model obtained from the reflectivity method provides an excellent fit to the Soviet air-gun data, but how well does it model explosion refraction data from the same OBS in the same and different directions, and how does the model work with data from the borehole seis- mometer about $380 \mathrm{~m}$ below the OBS? The U.S.N.S. De Steiguer ran an explosive refraction line along approximately the same track as the Soviet air-gun line (Fig. 3). These shots were recorded by HIG OBS 220, the same OBS that recorded the Soviet air gun. Comparison of the data (Fig. 4 and 5) and the synthetics (Fig. 8) shows immediately why modeling was done with the air-gun data rather than the explosive data. The spacing between traces in the explosive data is much larger, the correlation from trace to trace is very low, the origin time is less certain, and many of the traces are clipped because of the limited dynamic range of the recording system. Even so, the similarity between the explosive data and the synthetics is quite clear.

The explosive data show the mantle refraction (arrival $P_{n}$ in Fig. 12) more clearly than the air-gun data because of the greater source strength of the explosives. Comparison of the mantle refraction arrival times with the model implies that the true mantle velocity is somewhat faster than that of the model. Anisotropic velocity structure may be present in the mantle and is discussed by Bibee and Bee (in press).

Reflectivity synthetic seismograms were calculated for the borehole seismometer with the same model as above (Fig. 6) and are compared with the borehole explosion data from a short explosive line to the north of the site (Fig. 13), run after the OBSs were retrieved. As the OBS and OSS IV were within a few hundred meters of each other, it is expected that the same model should work with both data sets. Except for minor variations caused by uncertainties in navigation and origin time of the shots, the match between the synthetics and data is good, giving us some confidence in the validity of the model.

Data from an explosive refraction line to the east (Line 5 in Fig. 3) recorded by the OSS IV borehole instrument is shown in Figure 14. In this direction, significant differences in the mantle reflections (PmP and $\mathrm{SmS})$ are observed. The highest amplitudes are observed over a wider range of distances and appear to have more structure than indicated in the model. Whether these changes are caused by anisotropic effects or lateral variation in the crust/mantle boundary is uncertain.

\section{CONCLUSIONS}

A large (30-liter) air gun fired once per minute (about every $200 \mathrm{~m}$ ) yields much better refraction data on an ocean bottom seismometer than explosives of various sizes fired at various depths every kilometer. The coherence between air-gun arrivals is far better than for the explosives, and problems with spatial aliasing are virtually eliminated. For sub-crustal arrivals, the explosives yield superior data because of their greater source strength.

The trade-offs between use of a borehole seismometer package or an ocean bottom seismometer for refraction studies are discussed in terms of relative signal-tonoise in Duennebier et. al. (this volume) and Bibee and Bee (in press). We observe from the data presented in this chapter that the ocean bottom seismometer is more helpful in determination of sediment structure than the borehole seismometer. This is because of the large dif- 
F. K. DUENNEBIER ET AL.
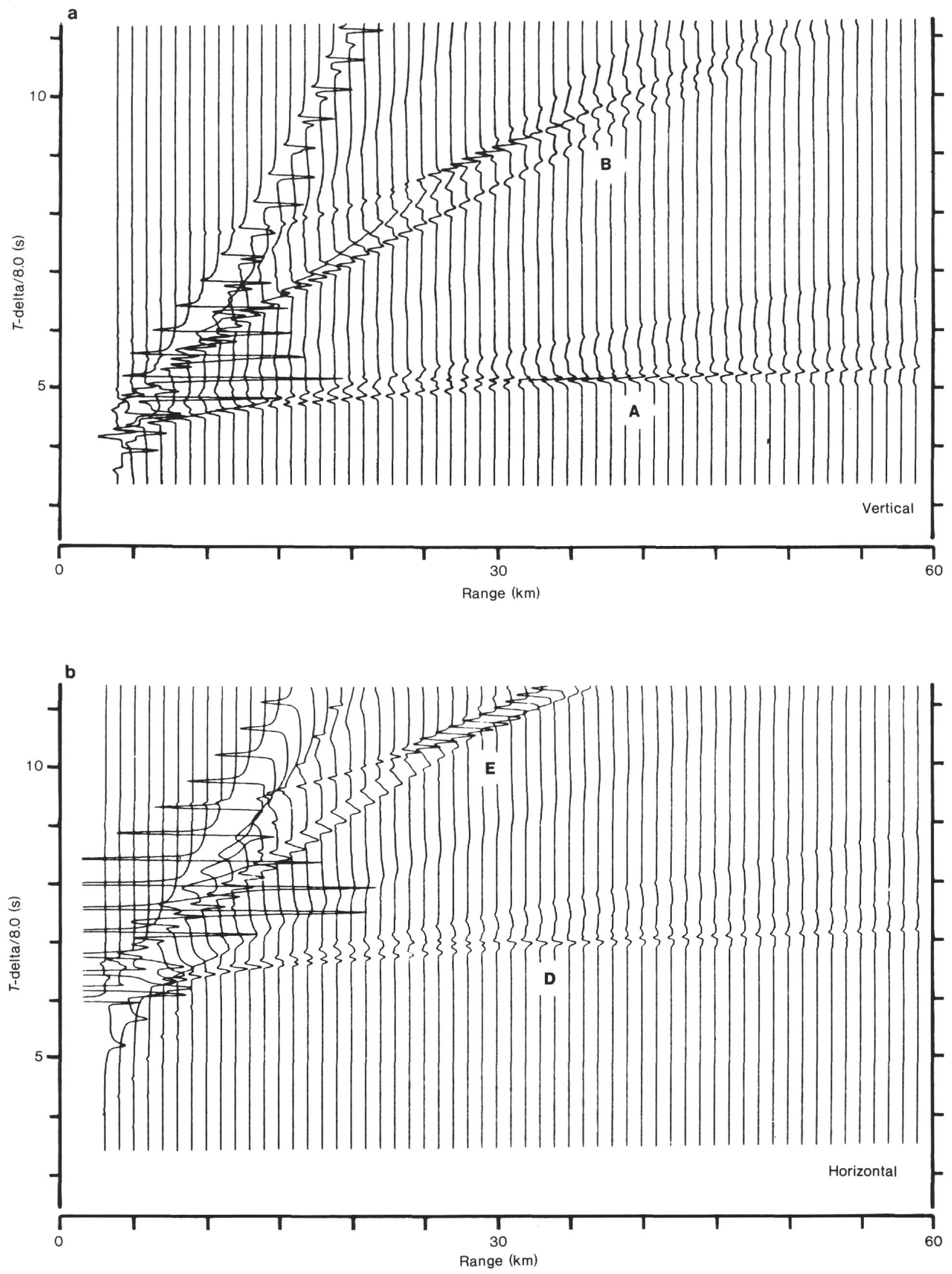

Figure 7. Synthetic seismogram record sections from WKBJ forward modeling of Soviet air-gun data. Synthetic seismograms represent the impulse response and have not been convolved with a source wavelet. The model used is shown in Figure 6. Rays used in calculating Figure 7a (vertical) are shown as rays A, B, and C in Figure 12a. Those used in Figure 7b (horizontal) are rays C, D, E, and F in Figure $12 \mathrm{a}$. 


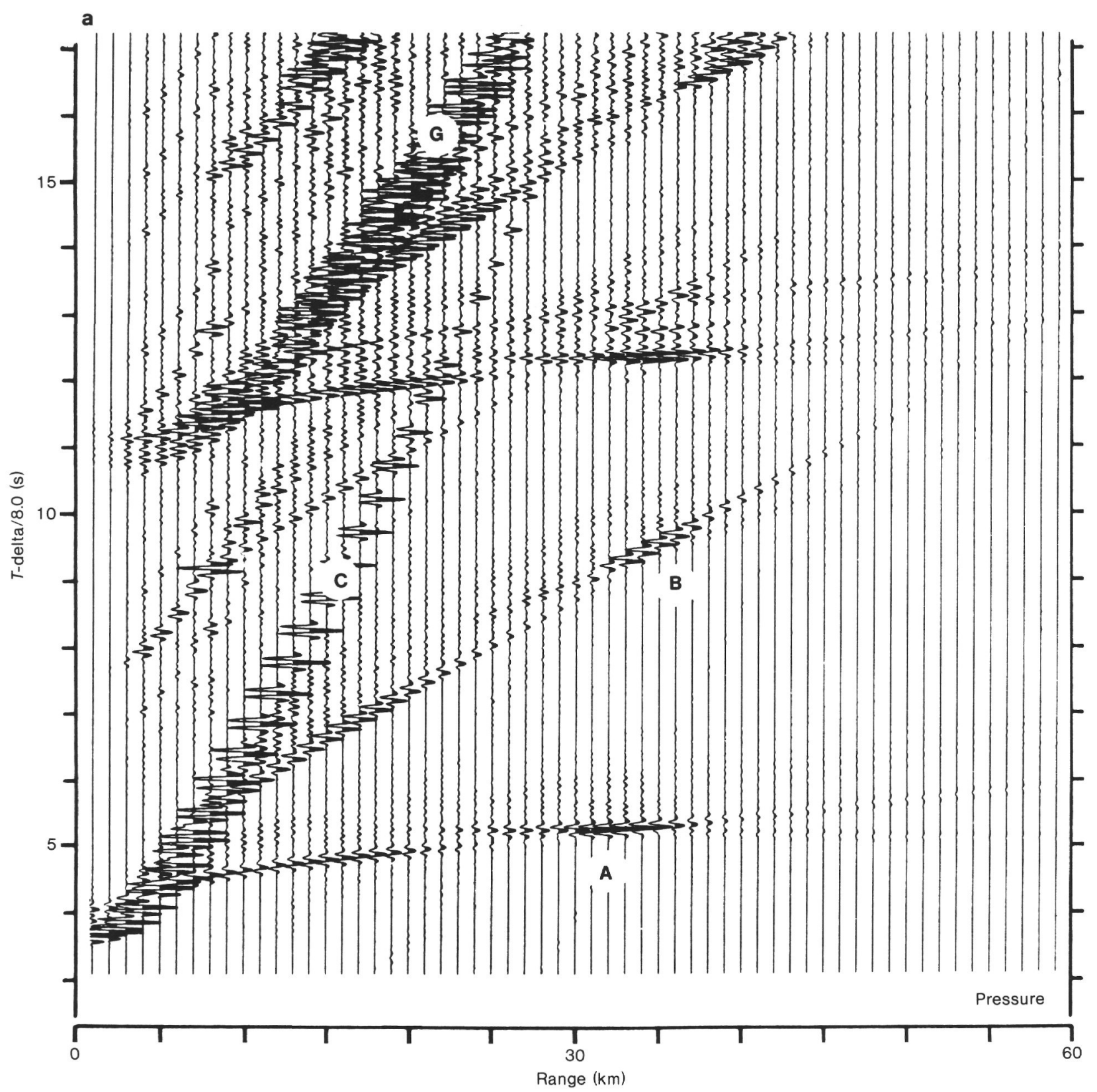

Figure 8. Synthetic seismogram record sections from reflectivity forward modeling. The synthetic record sections are plotted at the same scale as Figure 4 for comparison. The synthetic seismograms are band-pass filtered from 8 to $13 \mathrm{~Hz}$ and corrected for $r^{-1}$ spreading. The model used to calculate the synthetics is displayed in Figure 6. The model is complete for slowness values of 0.0001 to $1.0 \mathrm{~s} / \mathrm{km}$. Figure $8 \mathrm{a}, \mathrm{b}$, and $\mathrm{c}$ and are pressure, vertical, and horizontal displacements, respectively.

ference between the shear and compressional traveltimes in the sediments, and the fact that clear arrivals traveling as shear in the sediments are better observed on the ocean floor than in the borehole.

The structural interpretation presented in this report is not final but does appear to support a low-velocity zone in both compressional and shear velocities in Layer 3, as also noted by Anosov et al. (1982). The interpretation also supports a transition zone from crust to mantle approximately $1 \mathrm{~km}$ thick, as noted by Bibee and Bee (in press). Neither of these conclusions can be drawn from traveltimes alone; they depend on detailed analysis of the amplitudes of arrivals. Very good agreement be- tween reflectivity synthetic seismograms and the refraction data has been obtained for both ocean bottom seismometers and the borehole seismometer with the same elastic model.

The clear separation of the compressional and shear arrivals on the hydrophone, vertical, and horizontal geophones of the ocean bottom seismometers is caused by the very low shear velocity in the sediments. Shear conversion at the base of the sediments yields strong vertically traveling shear waves seen on the horizontal geophone, arriving about $1.8 \mathrm{~s}$ after the compressional arrivals seen on the vertical component. Further study of the shear arrivals may yield high-resolution information 


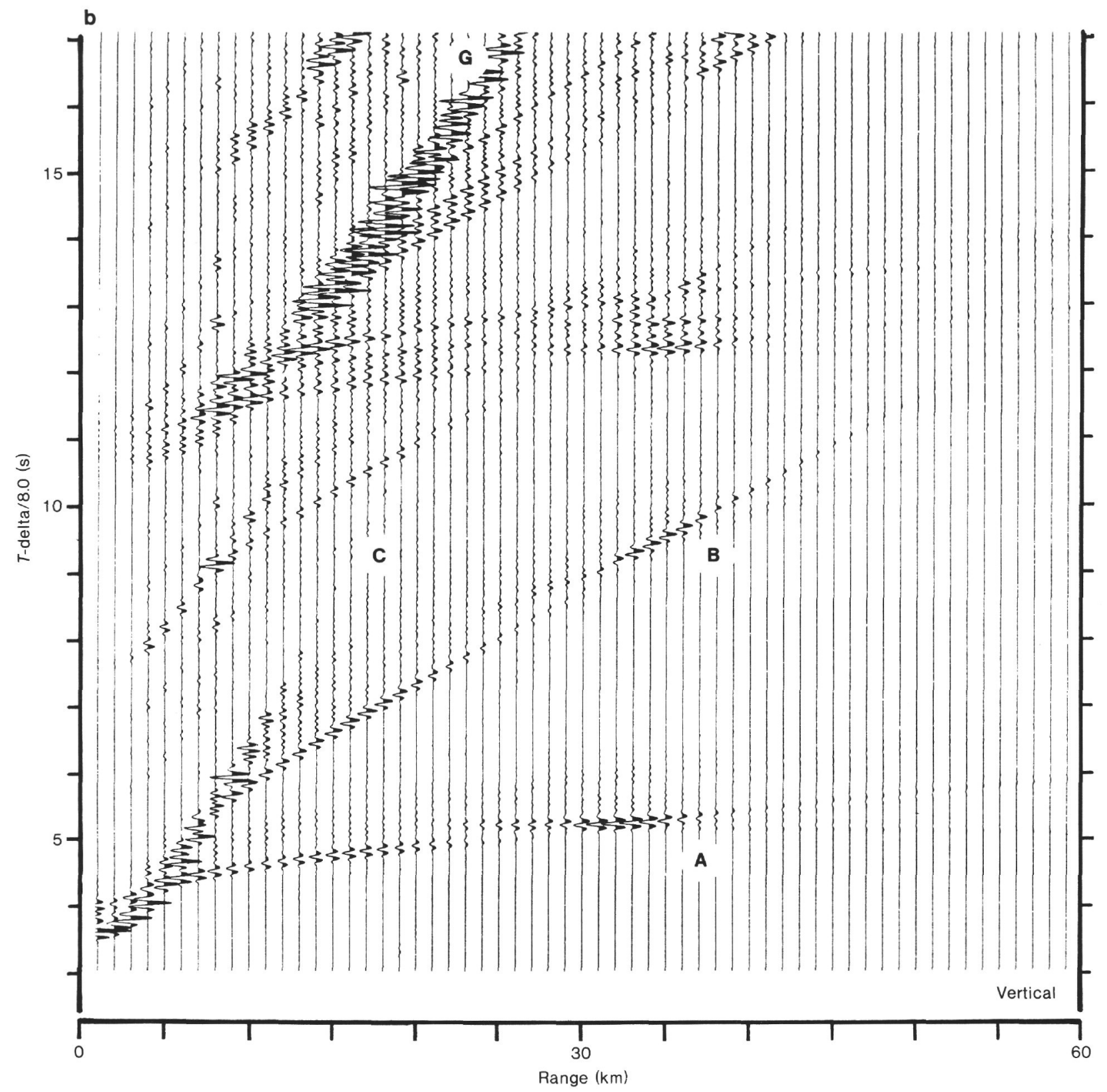

Figure 8 (continued).

about the sediments that cannot be obtained from the compressional arrivals because of their much longer wavelength.

\section{ACKNOWLEDGMENTS}

We thank the scientists, staff, and crews of Glomar Challenger, U.S.N.S. De Steiguer, and Dimitri Mendeleev for their valuable contributions to this experiment. We give special thanks to Dr. Yuri Neprochnov for supplying us with the data necessary to perform the analysis of the Soviet air-gun data. Without the logistics and programmatic support of the Deep Sea Drilling Project, this project would not have been possible. Special thanks also go to the Hawaii Institute of Geophysics Engineering Support Facility for their efforts in making the ocean sub-bottom seismometer and the HIG ocean bottom seismometer systems the reliable and valuable systems that they have become. Most figures in this report were produced by the HIG Harris Computer Facility; others and much of the graphics were done by the HIG Graphics facility. This report has been internally edited and reviewed by Rita Pujalet, Diane Henderson, Dr. Gerard Fryer, and Dr. L. N.
Frazer. This project was funded by the Office of Naval Research. HIG contribution Number 1698.

\section{REFERENCES}

Anosov, G. I., Argentov, V. V., and Gnibidenko, H.S., 1982. Crustal low-velocity zone south of Shatsky Rise, northwest Pacific Ocean. Geo-Mar. Lett., 2:17-21.

Asada, T., and Shimamura, H., 1976. Observations of earthquakes and explosions at the bottom of the western Pacific: Structure of the oceanic lithosphere revealed by longshot experiment. Am. Geophys. Union Monogr., 19:138-153.

Bessanova, E. N., Fishman, V. M., Ryaboyi, V. Z., and Sitniknova, G. A., 1974. The tau method for inversion of travel times-I. Deep seismic sounding data. Geophys. J. R. Astron. Soc., 36:377-398.

Bibee, L. D, and Bee, M., in press. A seismic refraction study of Cretaceous oceanic lithosphere in the northwest Pacific Ocean. J. Geophys. Res.

Byrne, D. A., Sutton, G. H., Blackinton, J. G., and Duennebier, F., 1983. Isolated sensor ocean bottom seismometer. Mar. Geophys. Res., 5:437-449. 


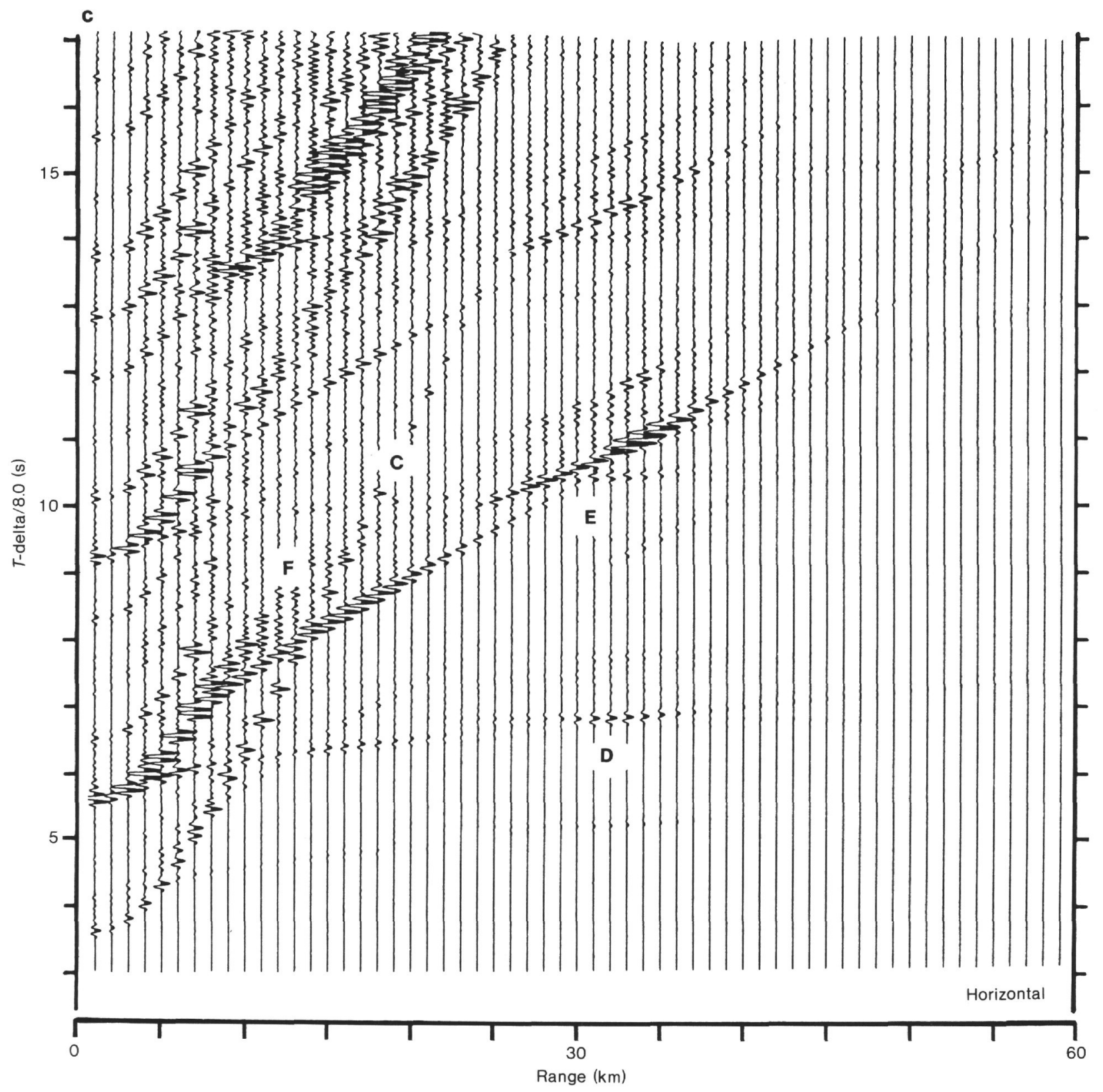

Figure 8 (continued).

Chapman, C. H., 1978. New method for computing synthetic seismograms. J. R. Astron. Soc., 54(3):481-518.

Dey-Sarkar, S. K., and Chapman, C. H., 1978. A simple method for the computation of body-wave seismograms. Bull. Seismol. Soc. Am., 68(6):1577-1593.

Diebold, J. B., and Stoffa, P. L., 1981. The traveltime equation, $\tau-p$ mapping, and inversion of common midpoint data. Geophysics, 46:(3):238-254.

Frazer, L. N., and Gettrust, J. F., 1984. On a generalization of Filon's method and the computation of oscillatory integrals of seismology, Geophys. J. R. Astron. Soc., 76:461-481.

Fuchs, K., and Müller, G., 1971. Computation of synthetic seismograms with the reflectivity method and comparison with observations, Geophys. J. R. Astron. Soc., 23:417-433.

Jackson, D. D., 1972. Interpretation of inaccurate, insufficient, and inconsistent data. Geophys. J. R. Astron. Soc., 28:97-109.

Kennett, B. L. N., 1974. Reflections, rays and reverberations. Bull. Seismol. Soc. Am., 64(6):1685-1696.

Kennett, B. L. N., and Kerry, N. J., 1979. Seismic waves in a stratified half space. Geophys. J. R. Astron. Soc., 57:557-583.
Kennett, B. L. N., and Orcutt, J. A., 1976. A comparison of travel time inversions for marine refraction profiles. J. Geophys. Res., 81(23):4061-4070.

Mallick, S., and Frazer, L. N., in press. Practical aspects of reflectivity modelling. Geophysics.

Spudich, P., and Orcutt, J., 1980a. A new look at the seismic velocity structure of the ocean crust. Rev. Geophys. Space Phys., 18(3): 627-645.

1980b. Petrology and porosity of an ocean crustal site: Results from wave form modeling of seismic refraction data. J. Geophys. Res., 85(B3):1409-1433.

Stoffa, P. L., Buhl, P., Diebold, J. B., and Wenzel, F., 1981. Direct mapping of seismic data to the domain of intercept time and ray parameter-A plane wave decomposition. Geophysics, 46(3):255267.

Wiggins, R. A., 1972. The general linear inverse problem: Implications of surface waves and free oscillations for earth structure. Rev. Geophys. Space Phys., 10:251-285.

Date of Initial Receipt: 6 September 1985

Date of Acceptance: 27 February 1986 
F. K. DUENNEBIER ET AL.
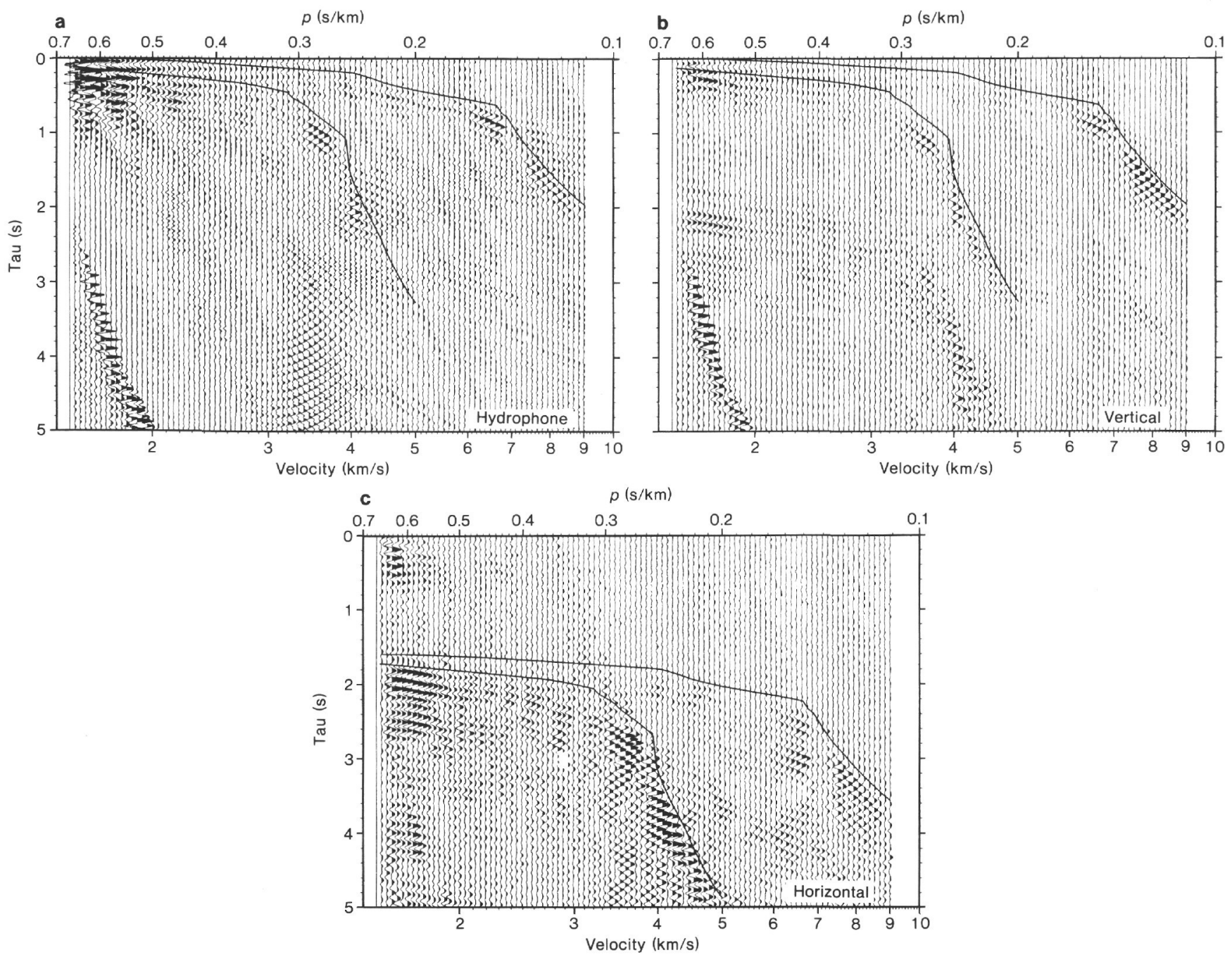

Figure 9. $\tau-p$ transformation. The OSS Soviet air-gun data in Figure 4 are plotted in the $\tau-p$ plane. The solid line on each plot is the theoretical minimum or caustic calculated using the $\tau-p$ models presented in Figure 6. 


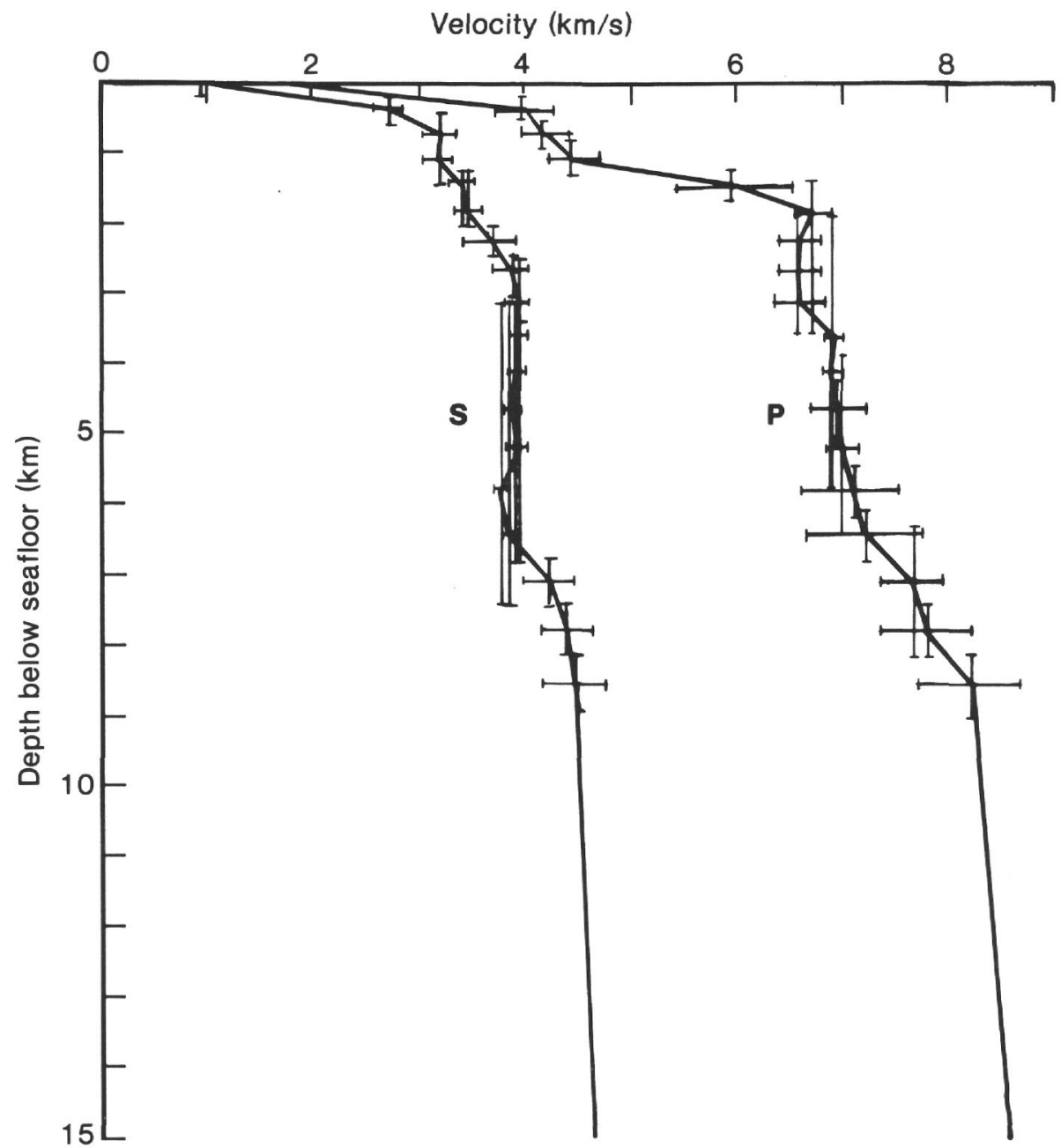

Figure 10. $\tau-p$ velocity-depth model showing the precision of layer boundary velocity estimates (horizontal lines), and resolution in depth (vertical lines). The poor depth resolution in the lowvelocity zones is the result of the lack of arrivals from those regions. 

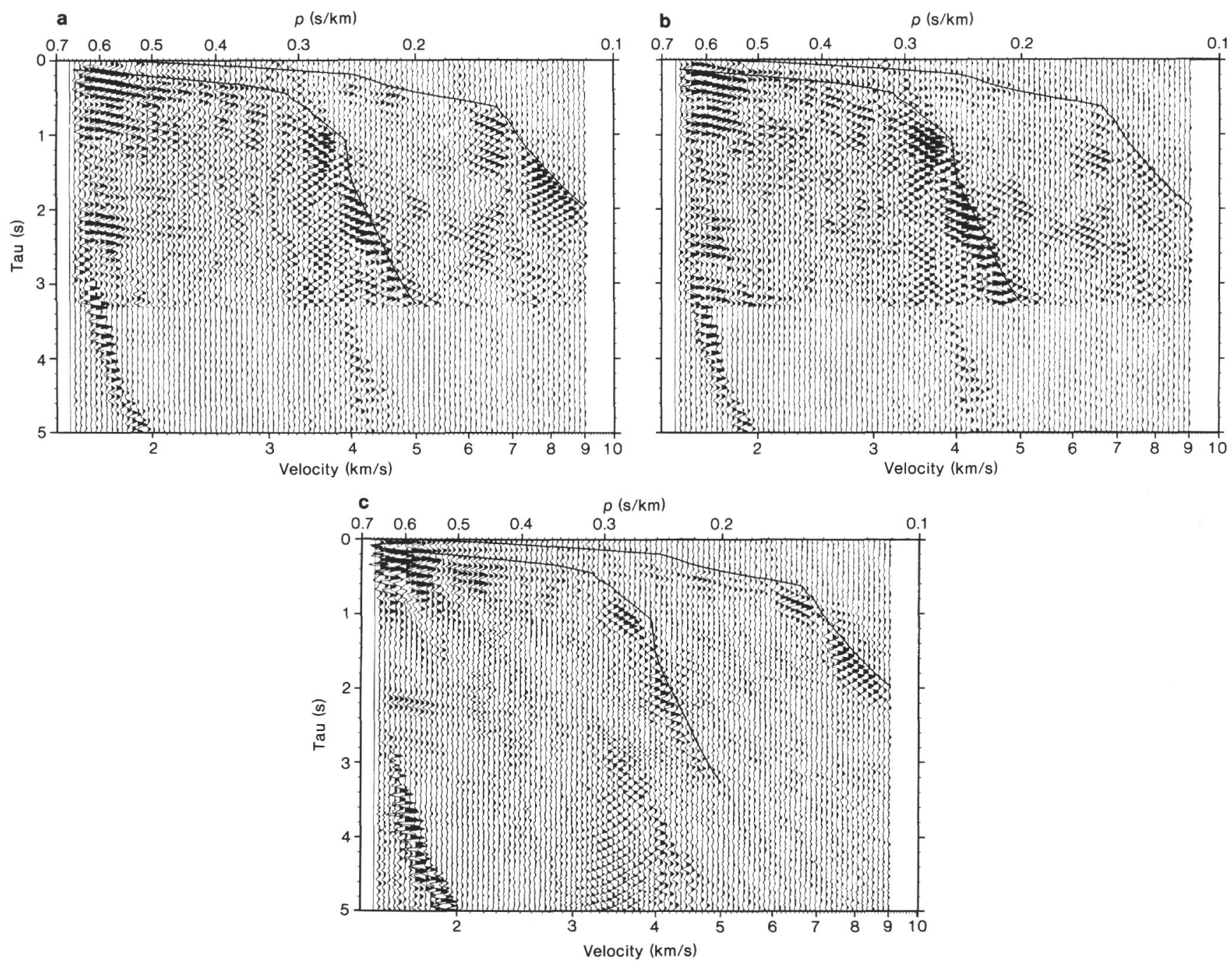

Figure 11. Combinations of the vertical and horizontal OSS-Soviet air gun data in the $\tau-p$ plane allow enhancement of various arrivals. Figure 11a shows the vertical added to the horizontal (offset by $1.8 \mathrm{~s}$ ) enhancing the compressional arrivals; Figure 11b shows the vertical minus the horizontal (offset by $1.8 \mathrm{~s}$ ) emphasizing the shear arrivals. Figure 11c shows the hydrophone minus vertical, which discriminates against the direct water arrival for ease in picking the lower velocity portion to the $\tau-p$ curves. 


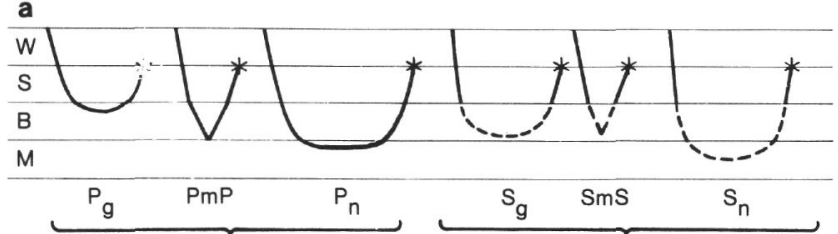

(A)

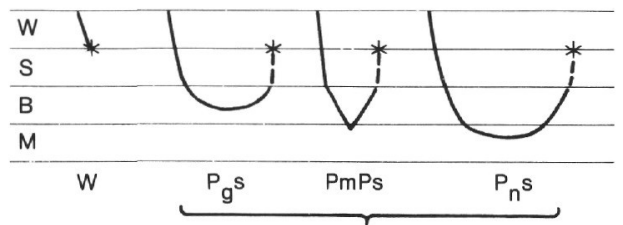

(D)

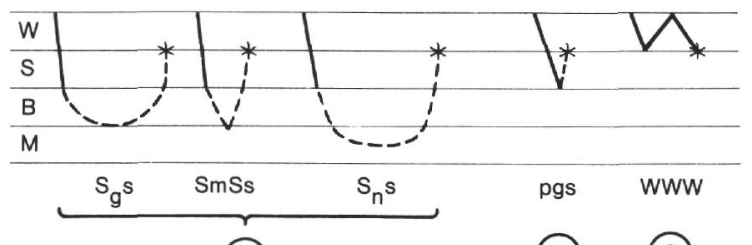

()

(a)

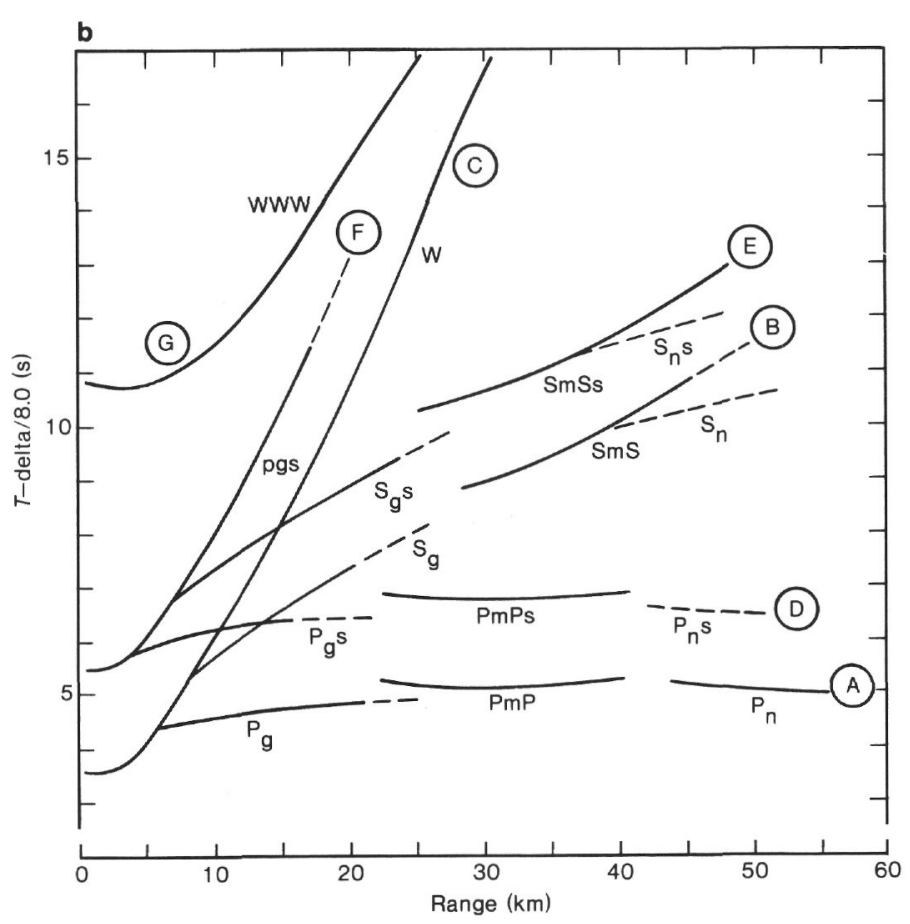

\begin{tabular}{|c|c|c|}
\hline Arrival & Description & Phase designations \\
\hline A & Compressional along whole path & $\mathrm{P}_{\mathrm{g}}, \mathrm{PmP}, \mathrm{P}_{\mathrm{n}}$ \\
\hline B & $\begin{array}{l}\text { Compressional in sediments, shear } \\
\text { in basement and mantle. }\end{array}$ & $s_{g}, S m s, s_{n}$ \\
\hline C & $\begin{array}{l}\text { Compressional wave in water } \\
\text { (direct water wave) }\end{array}$ & W \\
\hline $\mathrm{D}$ & $\begin{array}{l}\text { Compressional along whole path until } \\
\text { conversion to shear at sediment/ } \\
\text { basement interface on return to } \\
\text { ocean floor }\end{array}$ & $P_{g} s, P m P s, P_{n} s$ \\
\hline$E$ & $\begin{array}{l}\text { Converted to shear on way down at } \\
\text { sediment/basement boundary, } \\
\text { continuing as shear for remainder } \\
\text { of path }\end{array}$ & $S_{g} s, S m S s, S_{n} s$ \\
\hline $\mathrm{F}$ & $\begin{array}{l}\text { Converted to shear on reflection from } \\
\text { sediment/basement interface }\end{array}$ & $\mathrm{P}_{\mathrm{g}} \mathrm{S}$ \\
\hline G & Multiple water wave & WWW \\
\hline
\end{tabular}

Figure 12. Arrivals labeled on record sections. a. Ray diagrams showing ray paths of phases. b. Record section showing arrival times and distances of phases. Letter designations use the nomenclature of Spudich and Orcutt (1980b). The WSBM vertical annotations stand for water, sediment, basement, and mantle, respectively. 

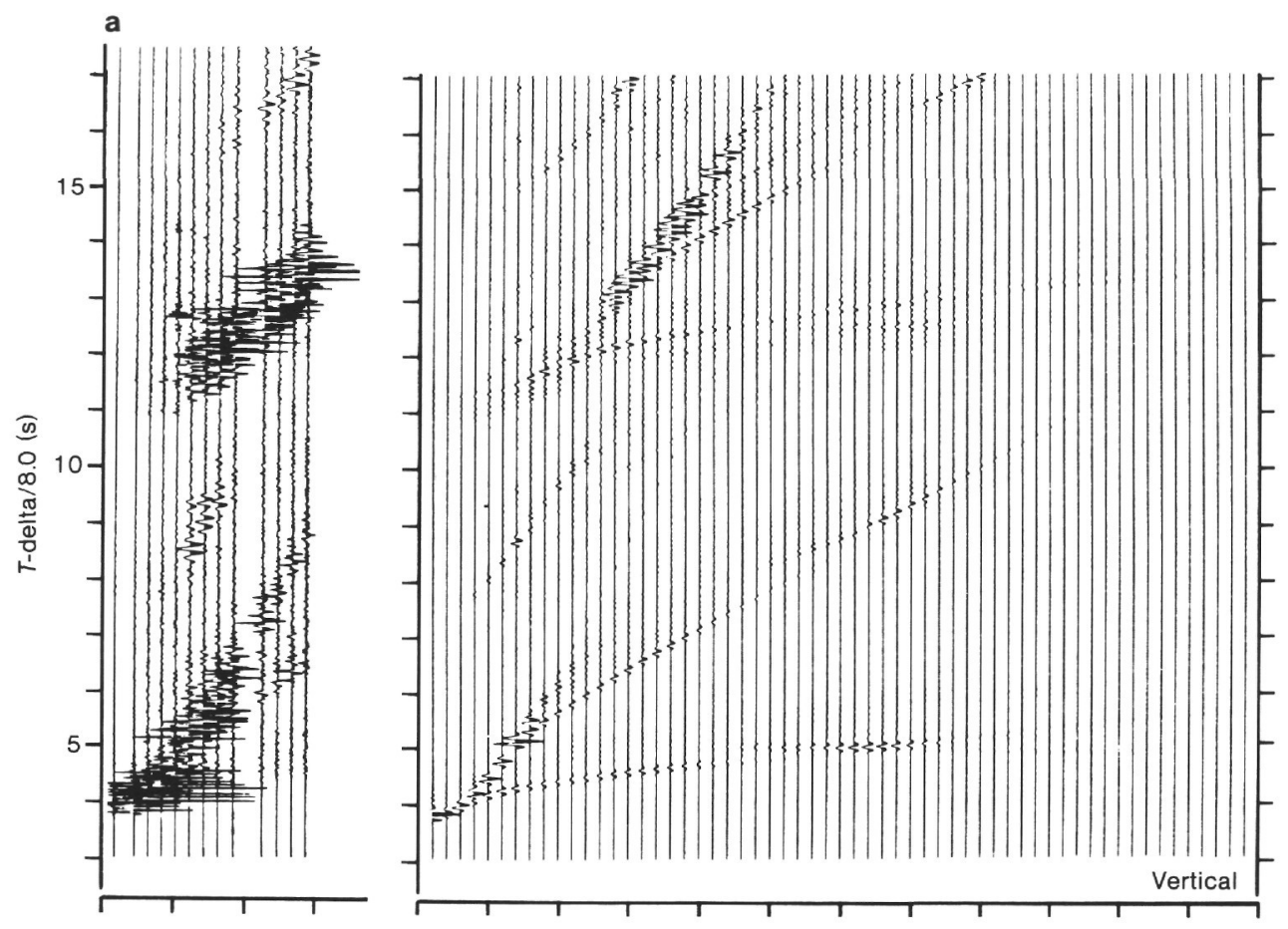

b
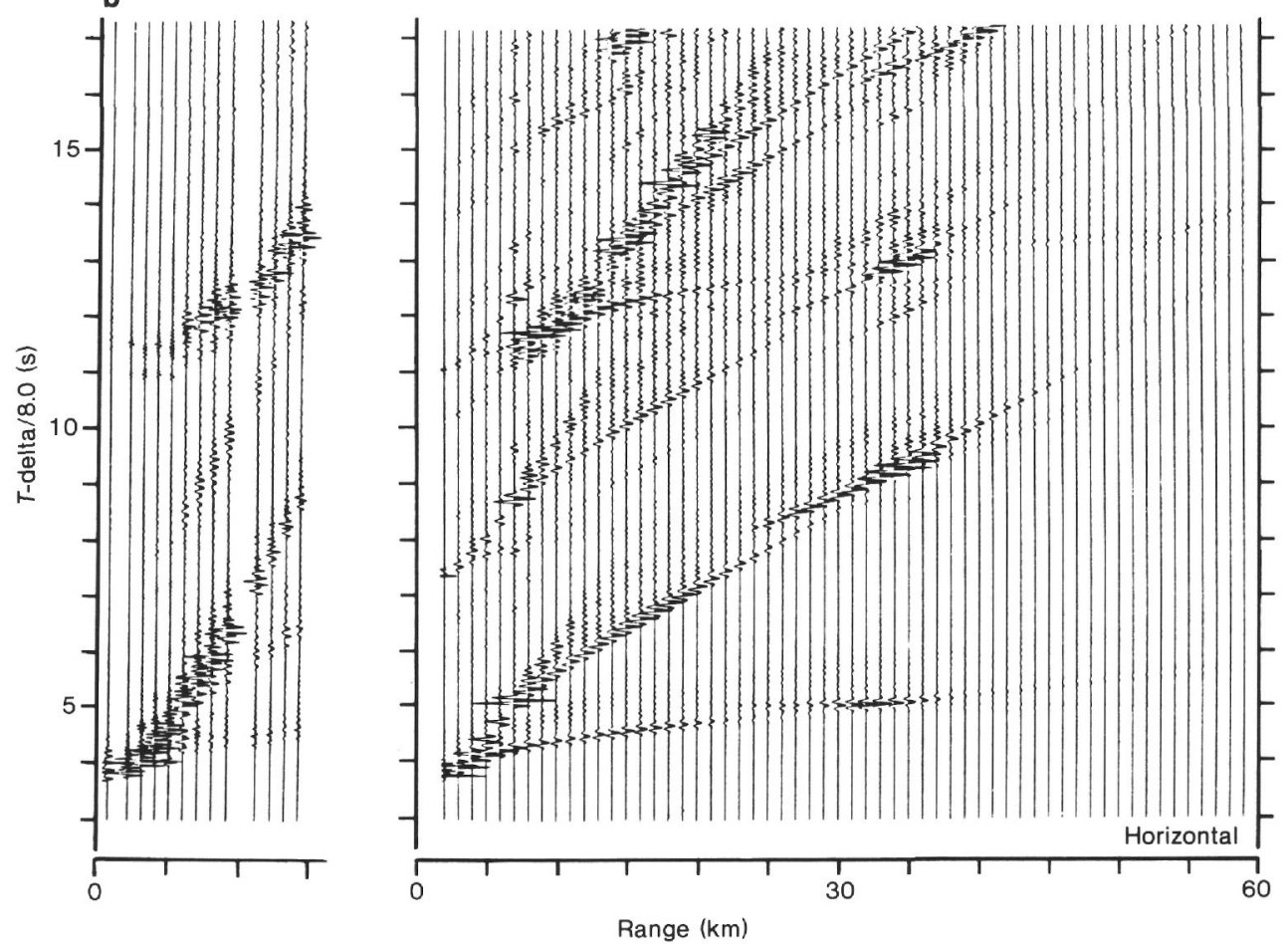

Figure 13. Sub-bottom seismometer data and reflectivity model synthetics. The reflectivity model obtained for the Soviet air-gun data (Fig. 6) was used to obtain synthetic seismograms for the borehole seismometer (left side), and is compared with data (right side) obtained from explosives on a short line in the same direction (see Fig. 3). Figures 13a and b show vertical geophone data and synthetics, and horizontal geophone data and synthetics, respectively. 

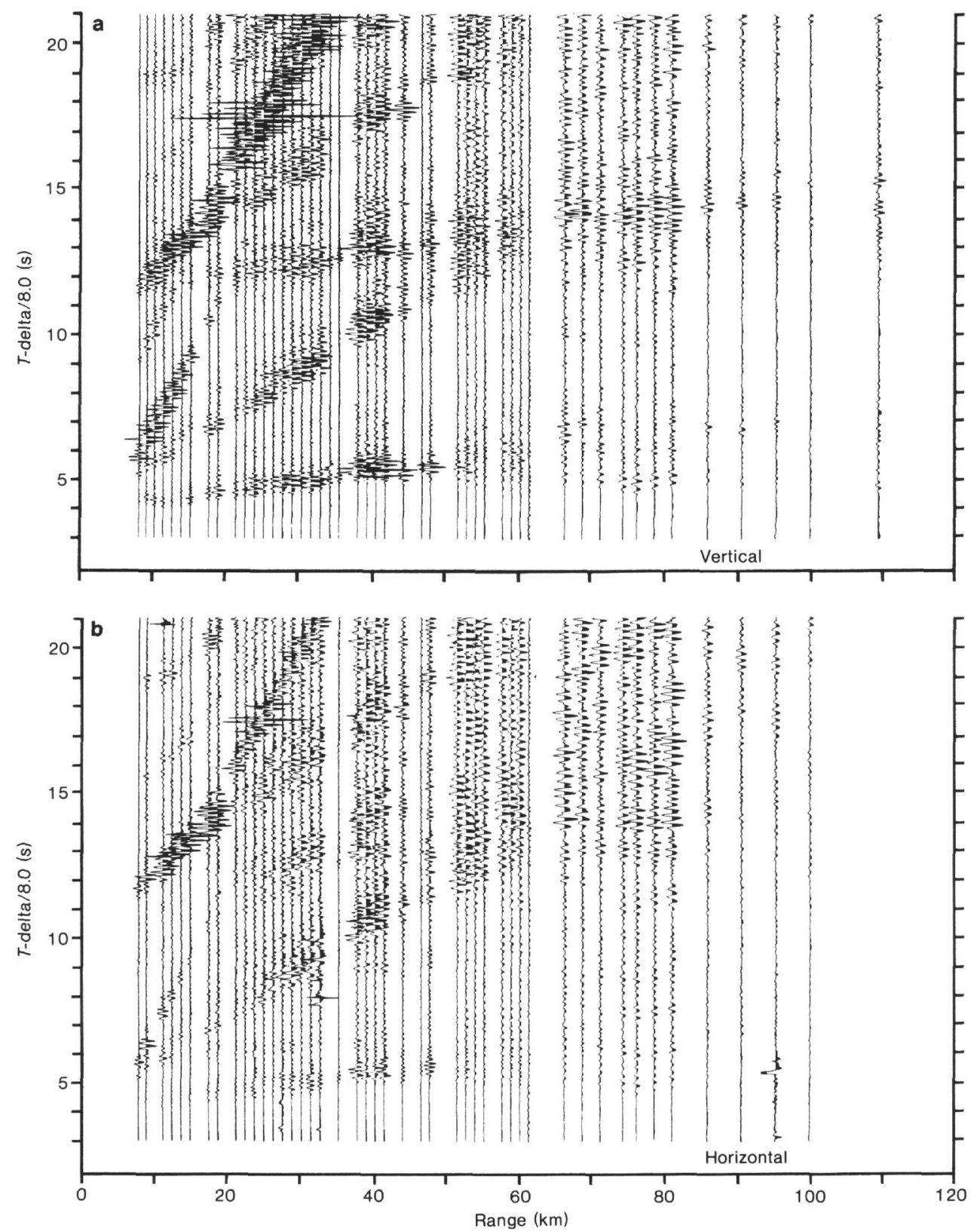

Figure 14. Ocean sub-bottom seismometer record sections from explosives on a line east of Site 581. a Vertical geophone. b. Horizontal geophone. These data have been corrected for $r^{-2}$ spreading and are bandpass filtered from 0.5 to $5 \mathrm{~Hz}$. 